\title{
Testing Typical Indian Buildings Under Different Extreme Temperature Conditions
}

\author{
F. Cecinati ${ }^{1}$, W. J. Chung ${ }^{1}$, S. Natarajan ${ }^{1}$, D. Coley ${ }^{1}$ \\ ${ }^{1}$ University of Bath, Architecture and Civil Engineering, Bath, UK
}

\begin{abstract}
Climate change has increased Indian temperatures and made heat waves more frequent and intense. Currently, only weather files for typical years exist for India. We test different extreme weather file designs, to identify which weather causes most impact on the indoor environment. We use an EnergyPlus model of a typical Indian residential buildings and observe how indoor temperatures and energy consumption vary with different weather file designs. We find that mean and maximum outdoor temperatures during the hot Indian season are not sufficient indicators for indoor conditions, but Design Summer Year and Summer Reference Year represent well extreme indoor conditions.
\end{abstract}

\section{Introduction}

India is well known for its hot weather, but climate change has further increased temperatures since the beginning of the century (Pai et al., 2013). Climatic projections foresee that the increase of temperatures will continue throughout the century up to $6^{\circ} \mathrm{C}$ (Kumar et al., 2006). Heat waves will become more frequent, longer and more intense, affecting larger areas of the country and leading to increased mortality (Murari et al., 2015). However, when it comes to building design and energy calculations, the only available weather files for the country represent typical weather conditions (Huang et al., 2008).

The importance of modelling buildings considering extreme conditions has already been addressed and many formats for weather files representing extreme weather conditions have been proposed (Herrera et al., 2017). However, if multiple formats exist for representing the typical year, it is even more complicated to define how to represent extreme conditions, which variables to consider and what factors actually affect indoor temperature conditions, indoor comfort and energy consumption.

The Design Summer Year (DSY) aims at representing a hot year selecting the year falling in the middle of the upper quartile of time series in terms of summer mean temperature (CISBE, 2014). However, considering extreme seasonal conditions does not guarantee to select extreme condition at shorter time scales as well, and a more complex method to generate a Summer Reference Year (SRY) comparing the typical Test Reference Year (TRY) and DSY has been proposed by Jentsch et al., (2015). To improve the representation of extremes, the use of synthetic time series has been proposed for the
Design Reference Year (DRY) (Levermore et al., 2012). The Extreme Meteorological Year (XMY), instead uses a larger selection of variables to represent extreme conditions, similar to the Typical Meteorological Year (TMY), but selecting extremes for the baseline. Finally, the Hot Summer Year (HSY-1) has been recently introduce to target thermal discomfort, based on two versions: HSY-1 is based on the use of Weighted Cooling Degrees Hour (WCDH), while the HSY-2 on the Physiological Equivalent Temperature (PET).

In this work, we compare different designs for weather files representing extreme weather conditions. The files are built using 30 years of data from the QUMP climate model of the UK Met Office, downscaled at $25 \mathrm{~km}$ over India with the PRECIS regional model (Mcsweeney and Jones, 2010). The data is calibrated with ground stations from the World Meteorological Organization, available at variable temporal resolution for shorter time series in various Indian locations. Given the limited availability of recorded variables from these stations, only the DSY, SRY and HSY-1 formats are tested here, along with the TRY as reference for a Typical Year.

The weather file formats are compared to 30 years if data to evaluate their ability to represent outdoor and indoor temperature extremes during the hot Indian season, and extreme values of yearly energy consumption. We use an EnergyPlus model of a typical Indian residential building in seven Indian cities with different geographical characteristics.

\section{Data and Model}

\section{Weather Data}

A combination of the UK Met Office probabilistic general circulation model QUMP and the regional climatic model PRECIS provides continuous hourly data between 1970 and 2100 on a $25 \mathrm{~km}$ grid over the whole Indian subcontinent. From this dataset, the weather between 1971 and 2000 has been extracted for the cities of Ahmedabad, Chennai, Dehradun, Hyderabad, Kolkata, Mumbai and New Delhi (Figure 1). The cities were selected to be representative of different climatic areas of the country. Dry bulb temperature, and air pressure were calibrated using data from the World Meteorological Organisation (WMO) ground stations with a quantilequantile regression, while dew point temperature was recalculated from the calibrated values of dry bulb temperature (A. L. Buck, 1981). The calibration resulted 
in a reduction of RMSE of $4.35 \%$ and $68.06 \%$ for dry bulb temperature and surface pressure respectively.

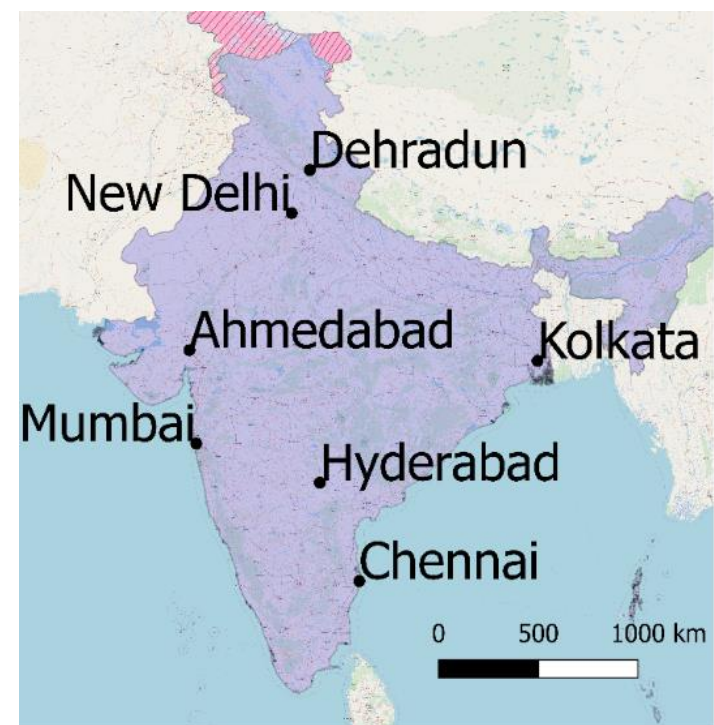

Figure 1 - The seven studied cities are representative of different climates and landscapes in India.

Global horizontal radiation, direct normal radiation, diffuse horizontal radiation, and horizontal infrared radiation are derived from the QUMP/PRECIS surface downwelling shortwave and longwave radiations following the methodologies from Ridley et al., (2010) and Boland et al., (2013). However, due to a lack of radiation data in the WMO dataset, these variables could not be calibrated.

\section{EnergyPlus Model}

In order to evaluate weather files, a typical residential building from Global Building Performance Network (Rawal and Shukla, 2014) was modelled with EnergyPlus v.8.8 [R1]. Boundary conditions for simulation are described in Table 1 and overview and floor plan for each flat is demonstrated in Figure 2 and 3.

Table 1 Simulation conditions

\begin{tabular}{|c|c|}
\hline Conditions & Content \\
\hline Area & $284 \mathrm{~m}^{2}$ (3 story b., 4 flats per floor) \\
\hline $\begin{array}{c}\text { Internal heat } \\
\text { gain }\end{array}$ & $\begin{array}{c}\text { People, lighting, equipment : 1person } \\
\text { per flat, } 5 \mathrm{~W} / \mathrm{m}^{2} 3.58 \mathrm{~W} / \mathrm{m}^{2}\end{array}$ \\
\hline $\begin{array}{c}\text { Setpoint } \\
\text { temperature }\end{array}$ & $26^{\circ} \mathrm{C}$ (summer) \\
\hline $\begin{array}{c}\text { Type of cooling } \\
\text { system }\end{array}$ & Packaged Terminal Air Conditioner \\
\hline $\begin{array}{c}\text { Cooling } \\
\text { location }\end{array}$ & Living room and Bedroom \\
\hline
\end{tabular}

\section{Weather file generation and evaluation}

\section{Selected weather file designs}

In literature, many designs for typical and extreme weather files have been proposed. In this work we select three extreme weather file designs:

- Design Summer Year (DSY)

- Summer Reference Year (SRY)

- Hot Summer Year version 1 (HSY-1)
As reference, we also consider the Test Reference Year (TRY), which refers to typical conditions. The TRY collates one year selecting the most average individual months from the reference time series. We calculate TRY files following the methodology by the BS EN ISO 15927-4:2005, (2005). However, given the fact that we could not calibrate solar radiation, we base our Finkelstein-Schafer (FS) statistics on equal weighting of dry bulb temperature, relative humidity and wind speed. The DSY is a whole year, selected as the middle of the upper quartile of summertime (April to September) average dry bulb temperature (Herrera et al., 2017). The SRY is based on the TRY, which is adjusted using the year that falls in the $90^{\text {th }}$ percentile year of average summer temperature (Jentsch et al., 2015). Finally, the HSY-1 (subsequently referred only as HSY) is selected as the year with the maximum weighted cooling degree hour (WCDH) over summer (June to August) (Liu et al., 2016). For details about calculations the reader is referred to the respective sources.

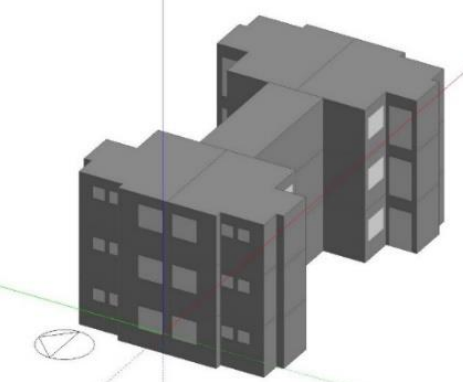

Figure 2 - Overview of GBPN typical Indian building.

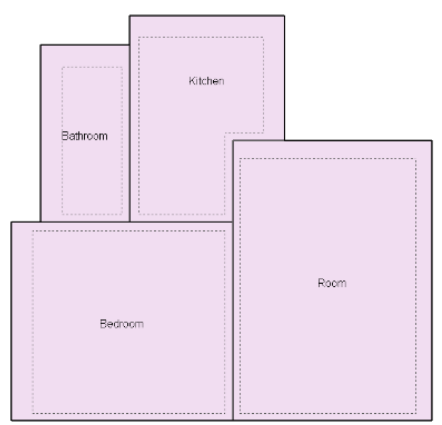

Figure 3-Plan for each flat of the typical Indian building

TRY, DSY, SRY and HSY are calculated for each of the seven study cities, and run into the EnergyPlus model of the typical Indian building.

\section{Evaluation}

The generated weather files are evaluated both in terms of ability to represent outdoor extreme weather conditions and in terms of ability to represent indoor extreme conditions. In India, the hottest month of the year is typically May, and the hot season goes from April to June, before the monsoon season starts. Figure 4 shows the climatological monthly temperature, averaged over the study cities, calculated with 30 years of QUMP data. 
Climatological Monthly Temperature

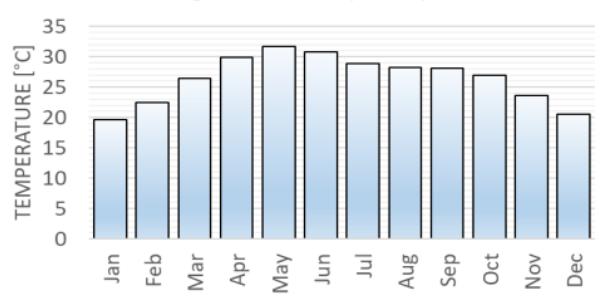

Figure 4 - Climatological monthly average temperature, averaged over the seven study cities in Figure 1

Considering the climatic characteristics of India, the following criteria are compared for outdoor temperature, for each of the weather files:

1. Mean outdoor temperature in May (TOmean5)

2. Mean outdoor temperature in April, May, June (TOmean456)

3. Max outdoor temperature reached in May (TOmax5)

4. Max outdoor temperature reached in April, May, June (TOmax456)

5. Weighted cooling degree hour over the year (WCDH)

WCDH, calculated as in CISBE, (2014), represent how much the temperature has exceeded a comfortable threshold. While May is usually the hottest month, the yearly maximum temperature is not always reached in May, but almost always in April, May, or June. Therefore TOmax456 also represents the maximum yearly temperature well.

After running the EnergyPlus simulation without air conditioning, indoor temperature are obtained for each of the rooms, on each of the floors. The temperature are then averaged at building level. Subsequently, simulations are run with air conditioning, obtaining energy consumption for each room at hourly scale. Energy consumption is then summed at building level and over the year. Therefore the weather files are compared using the following indoor condition criteria:

6. Mean indoor temperature in May (TImean5)

7. Mean indoor temperature in April, May, June (TImean456)

8. Max indoor temperature reached in May (TImax5)

9. Max indoor temperature reached in April, May, June (TImax456)

10. Yearly energy consumption (Ey)

The criteria are calculated for each of the reference years (1971-2000) and each of the weather files; the weather files are then ranked in terms of percentiles they represent compared to the reference years, for each of the criteria.

\section{Simulation Results}

The results for the five considered outdoor criteria are presented in Figure 5 for the city of New Delhi. Results for the other six cities are similar and consistent, therefore they are reported only in the Appendix (Figures S1 to S6).
New Delhi

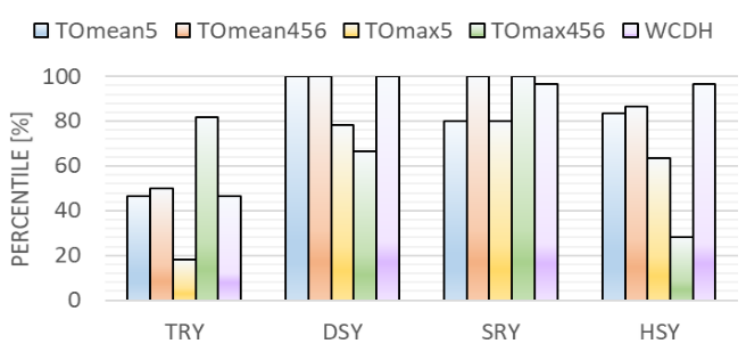

Figure 5 - The four considered weather files are compared in terms of their ranking as percentiles compared to the reference 30 years, following the five presented criteria for outdoor conditions, for New Delhi.

Similarly, Figure 6 shows how the four weather files compare in terms of indoor conditions, again expressed in terms of percentile referred to the 30 -year baseline, for the city of New Delhi. Similar plots for the other six cities are reported in the Appendix (Figures S7 to S12).

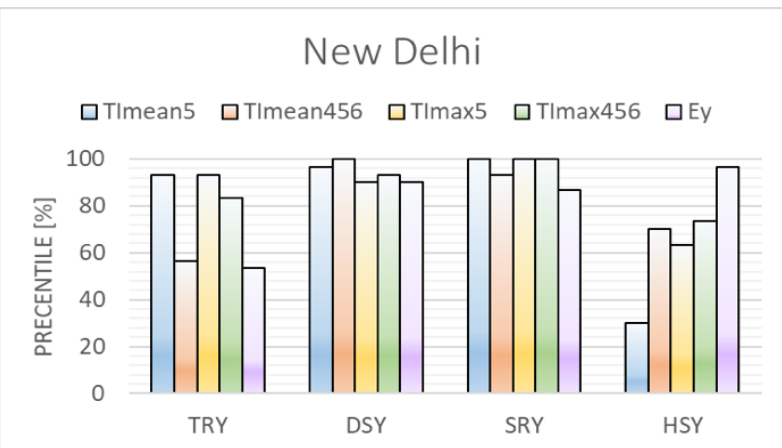

Figure 6 - The four considered weather files are compared in terms of their ranking as percentiles compared to the reference 30 years, following the five presented criteria for indoor conditions, for New Delhi.

As regards energy consumption, Table 2 reports the annual consumption for each city. Table 3 instead reports the average percentage that the months of April, May and June represent over the year (as the difference between cities is limited).

Table 2 Yearly energy consumption [MWh]

\begin{tabular}{|c|c|c|c|c|}
\hline & TRY & DSY & SRY & HSY \\
\hline New Delhi & 9.8 & 11.2 & 13.7 & 10.2 \\
\hline Ahmedabad & 12.7 & 11.8 & 13.7 & 10.1 \\
\hline Chennai & 13.0 & 12.5 & 13.8 & 10.7 \\
\hline Dehradun & 7.2 & 7.7 & 8.5 & 9.4 \\
\hline Hyderabad & 7.4 & 8.7 & 10.4 & 7.6 \\
\hline Kolkata & 9.1 & 10.6 & 12.3 & 8.9 \\
\hline Mumbai & 8.6 & 9.8 & 11.0 & 8.3 \\
\hline
\end{tabular}

Table 3 Average fraction of yearly energy consumption

\begin{tabular}{|c|c|c|c|c|}
\hline & TRY & DSY & SRY & HSY \\
\hline April & $9.5 \%$ & $8.7 \%$ & $7.6 \%$ & $9.3 \%$ \\
\hline May & $18.1 \%$ & $19.4 \%$ & $15.0 \%$ & $20.0 \%$ \\
\hline June & $24.6 \%$ & $16.6 \%$ & $17.8 \%$ & $23.5 \%$ \\
\hline
\end{tabular}

\section{Discussion and Result Analysis}

All the conclusions that can be drawn from the analysis of the results in New Delhi (Figures 5 and 6), are also 
representative of the results of the other seven cities (Figures S1 to S12), with the exception of Dehradun (Figure S3 and S9), which is looked at separately, later in this section.

Figures 5 and 6 represent the percentile that each of the weather files represent compared to the reference 30-year period, according to the different criteria. For example, in Figure 5 the TRY histogram bar reaches a $48^{\text {th }}$ percentile of TOmean5: it means that the $48 \%$ of the considered years had a lower outdoor mean temperature in May, while $52 \%$ a higher one, thus showing a good ability to represent average conditions for that criterion. As expected, TRY files represent average conditions, as concerns the mean outdoor temperature. This is shown by the first two bars of the TRY histogram in Figure 5, reaching values around the $50^{\text {th }}$ percentile. Similarly, TRY represent typical conditions of WCDH (fifth bar of TRY in Figure 5) an indicator of how much comfortable conditions have been exceeded throughout the year. However, the TRY methodology is not able to capture typical values of maximum outdoor temperature over the hot Indian months, as the third and fourth bars of the TRY histogram in Figure 5 show values far from the $50^{\text {th }}$ percentile. Similarly, it does not seem to be able to represent average indoor temperature conditions: with the exception of the mean temperature over April, May, and June, the other TRY criteria fall in a percentile much higher than the $50^{\text {th }}$ in Figure 6 . However, in terms of energy consumption the TRY is still able to represent average conditions (fifth TRY bar, Figure 6).

Looking at extreme files, SRY is the only one consistently representing high percentiles (above $80^{\text {th }}$ ) in terms of outdoor (Figure 5) and indoor (Figure 6) mean and maximum temperature, but also in terms of WCDH (fifth bar of SRY histogram in Figure 5) and yearly energy consumption (fifth bar of SRY histogram in Figure 6).

However, although the DSY design does not represent particularly extreme outdoor maximum temperature conditions (third and fourth bars of DSY histogram in Figure 5), it still represent very well extreme conditions of indoor temperature (DSY histogram in Figure 6), as well as extreme conditions of WCDH (fifth bar Figure 5) and yearly energy consumption (fifth bar Figure 6). These results lead us to hypothesize that maximum outdoor temperature in the month of May, or over the months of April, May and, June, are not critical factors determining the indoor temperature conditions.

Looking at HSY, instead, we see that it represents high, but not extreme, percentiles of outdoor mean temperature (first and second bars of HSY in Figure 5), but does not represent extreme conditions as concerns maximum outdoor temperatures (third and fourth bars of Figure 5), nor indoor temperatures (first to fourth bars of Figure 6). However, it still represents extreme values of WCDH and energy consumption. HSY is designed to consider summer over the months of June, July, and August, while SRY and DSY use a broader definition, April to September, which includes the hot Indian months. This is confirmed by Table 2, showing that HSY does not represent extreme energy consumption as well (often lower than TRY). Table 2 also shows that SRY is the only format consistently identifying higher energy consumption than the TRY format. Table 3 instead shows that energy consumption in June is significantly higher than April and May, although less so for extreme years, which may mean that the contribution toward energy consumption of less hot months may determine extreme energy consumption conditions. The only exception is the DSY, showing more energy consumed in May than June. The differences in trends between outdoor evaluation criteria and indoor evaluation criteria (Figure 5 vs Figure 6), especially for the TRY and HSY files, highlight that variables not included in the design of the weather files may have an important role in defining indoor temperatures, particularly solar radiation.

As concerns the analysis in the city of Dehradun, most conclusions seem to apply as well, but it can be noticed that the HSY seems to better represent outdoor conditions, while the TRY seems to better represent average indoor temperatures. Dehradun is a northern mountainous city, placed on the Himalayan foothills. It experiences lower temperatures than other Indian cities, but its climate is still well represented by a hot dry season followed by a monsoon season. The observed differences could be due to the slightly colder climate and a delayed start of the monsoon season due to the Northern position, but could also be driven by a different performance of the QUMP/PRECIS climatic model in modelling mountainous regions. However, none of the noted differences drastically change the presented analysis and it is remarkable to observe how little geography influences the results. This is a positive outcome, as a future continuation of this work aims to design a new extreme weather file for India: there will be no need to consider significant differences in representing extreme conditions throughout the Indian subcontinent.

Nonetheless, more analysis need to be conducted to include the impact of weather conditions during the monsoon season, to evaluate how other variables like relative humidity and solar radiation influence the indoor conditions, to consider other designs like the Typical Meteorological Year (TMY) or the Extreme Meteorological Year (XML) performance in India, and to evaluate if the change of the baseline to a more recent set of years influences the results. Additionally, we will work on techniques to calibrate solar radiation from alternative sources, in order to be able to use the variable in the weather file calculations and evaluate if the impact of the approximations used here influence our results.

\section{Conclusions}

The presented analysis is a non-exhaustive, but novel analysis of extreme weather files performance in India. The objective is to evaluate how to represent extreme weather conditions in the design of Indian buildings. A typical weather file, the Test Reference Year, as well as three different extreme weather file designs (the Design Summer Year, the Summer Reference Year and the Hot Summer Year version 1) are compared to a baseline of thirty years, from 1971 to 2000, in terms of indoor and outdoor temperature conditions, as well as energy 
consumption. A typical Indian building is modelled in EnergyPlus and indoor temperature conditions are estimated in case of no air conditioning, while the energy consumption over a year is simulated considering air conditioning in the building. Results are reported as the percentile that each weather file represents compared to the baseline years, according to five outdoor criteria and five indoor criteria.

Results show that:

- SRY seems the best candidate to represent extreme indoor and outdoor temperatures in India, as well as extreme yearly energy consumption.

- maximum outdoor temperatures seem to have a less important role in driving indoor temperatures, compared to mean outdoor temperatures;

- the differences between outdoor and indoor conditions highlight the role of variables not considered in the weather file designs in determining indoor temperature.

- the hot dry months of April, May, and June have a primary role in driving yearly energy consumption, but the monsoon months of June, July, August, and September may have a significant role as well, not analysed in this work;

- geography does not seem to represent a significant factor, as the results presented for seven cities throughout the Indian subcontinent do not show big differences;

- the limited availability of long reliable time series of solar radiation data is an obstacle for a thorough revision of weather file performance in India, but alternatives will be investigated.

More work needs to be conducted to evaluate the impact of approximations and of factors not considered in this work, but the presented results already show important insight about the requirements that a future extreme weather file format for India will need to have.

\section{Acknowledgement}

The research is funded by the EPSRC project Zero Peak Energy Building Design for India (EP/R008612/1). The authors thank the UK Met Office for the QUMP/PRECIS data and Dr. Chunde Liu and Daniel Fosas de Pando from the University of Bath for the support with calculations.

\section{References}

A. L. Buck, 1981. New equation for computing vapor pressure and enhancment factor. J. Appl. Meteorol. https://doi.org/10.1175/15200450(1981)020<1527:NEFCVP>2.0.CO;2

Boland, J., Huang, J., Ridley, B., 2013. Decomposing global solar radiation into its direct and diffuse components. Renew. Sustain. Energy Rev. 28, 749756. https://doi.org/10.1016/j.rser.2013.08.023

BS EN ISO 15927-4:2005, 2005. Hygrothermal performance of buildings - Calculation and presentation of climatic data. London.

CISBE, 2014. Design Summer Years for London, CISBE
TM49. London.

Herrera, M., Natarajan, S., Coley, D.A., Kershaw, T., Ramallo-González, A.P., Eames, M., Fosas, D., Wood, M., 2017. A review of current and future weather data for building simulation. Build. Serv. Eng. Res. Technol. 38, 602-627. https://doi.org/10.1177/0143624417705937

Huang, Y.J., Mathur, J., Murthy, V., Garg, V., 2008. Development of Typical Year Weather Files for 59 Indian Locations 3.

Jentsch, M.F., Eames, M.E., Levermore, G.J., 2015. Generating near-extreme Summer Reference Years for building performance simulation. Build. Serv. Eng. Res. Technol. 36, 701-721. https://doi.org/10.1177/0143624415587476

Kumar, K.R., Sahai, A.K., Kumar, K.K., Patwardhan, S.K., Mishra, P.K., Revadekar, J.V., Kamala, K., Pant, G.B., 2006. High-resolution Climate Change scenarios for India for the 21st Century. Curr. Sci. 90, 334-346.

Levermore, G., Courtney, R., Watkins, R., Cheung, H.K.W., Parkinson, J.B., Laycock, P., Natarajan, S., Nikolopoulou, M., McGilligan, C., Muneer, T., Tham, Y., Underwood, C.P., Edge, J.S., Du, H., Sharples, S., Kang, J., Barclay, M., Sanderson, M., 2012. Deriving and using future weather data for building design from UK climate change projections - an overview of the COPSE Project.

Liu, C., Kershaw, T., Eames, M.E., Coley, D.A., 2016. Future probabilistic hot summer years for overheating risk assessments. Build. Environ. 105, 56-68. https://doi.org/10.1016/j.buildenv.2016.05.028

Mcsweeney, C., Jones, R., 2010. Selecting members of the 'QUMP' perturbed-physics ensemble for use with PRECIS. Met Office Hadley Centre.

Murari, K.K., Ghosh, S., Patwardhan, A., Daly, E., Salvi, K., 2015. Intensification of future severe heat waves in India and their effect on heat stress and mortality. Reg. Environ. Chang. 15, 569-579. https://doi.org/10.1007/s10113-014-0660-6

Pai, D.S., Nair, S.A., Ramanathan, A.N., 2013. Long term climatology and trends of heat waves over India during the recent 50 years (1961-2010). Mausam 64, 585-604.

Rawal, R., Shukla, Y., 2014. Residential Buildings in India: Energy Use Projections and Saving Potentials. Ahmedabad.

Ridley, B., Boland, J., Lauret, P., 2010. Modelling of diffuse solar fraction with multiple predictors. Renew. Energy 35, 478-483. https://doi.org/10.1016/j.renene.2009.07.018 


\section{Appendix}

\section{Ahmedabad}

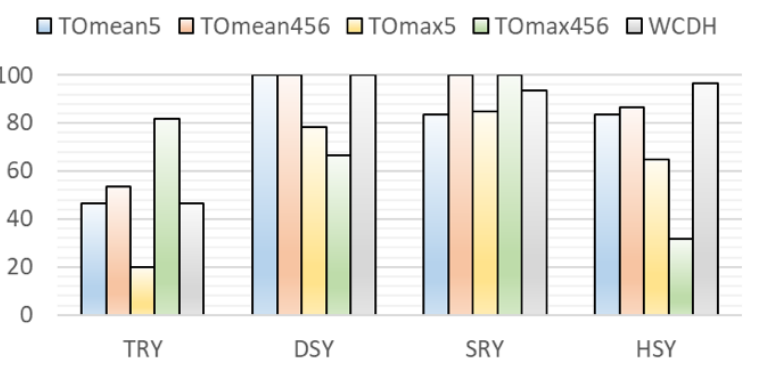

Figure S1 - The four considered weather files are compared in terms of their ranking as percentiles compared to the reference 30 years, following the five presented criteria for outdoor weather conditions for the city of Ahmedabad.

\section{Chennai}

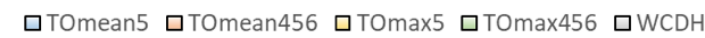

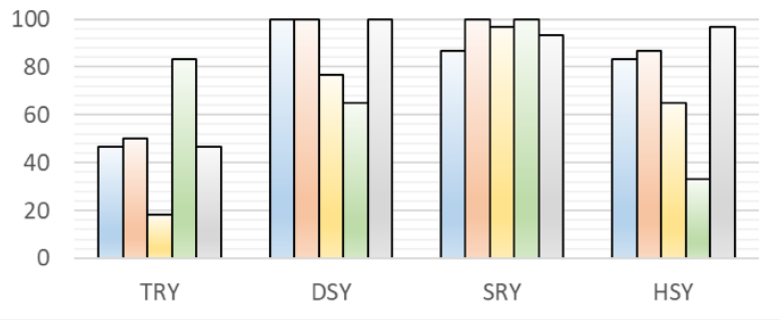

Figure S2 - The four considered weather files are compared in terms of their ranking as percentiles compared to the reference 30 years, following the five presented criteria for outdoor weather conditions for the city of Chennai.

\section{Dehradun}

口TOmean5 口TOmean456 口TOmax5 aTOmax456 םWCDH

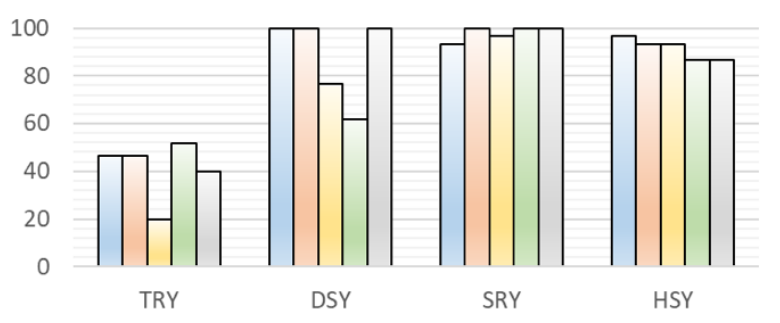

Figure S3 - The four considered weather files are compared in terms of their ranking as percentiles compared to the reference 30 years, following the five presented criteria for outdoor weather conditions for the city of Dehradun.

\section{Hyderabad}

口TOmean5 口TOmean456 口TOmax5 口TOmax456 口WCDH

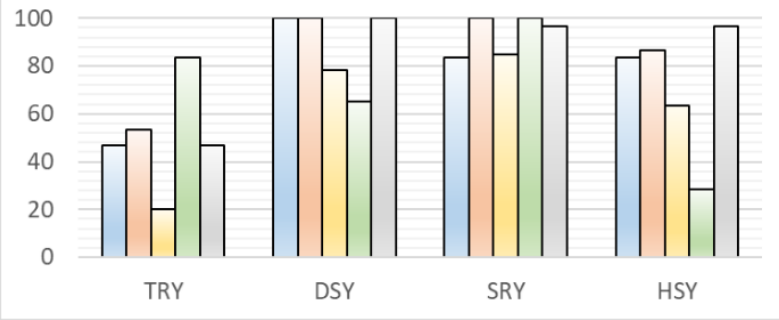

Figure S4 - The four considered weather files are compared in terms of their ranking as percentiles compared to the reference 30 years, following the five presented criteria for outdoor weather conditions for the city of Hyderabad.

Kolkata

口TOmean5 口TOmean456 口TOmax5 口TOmax456 aWCDH

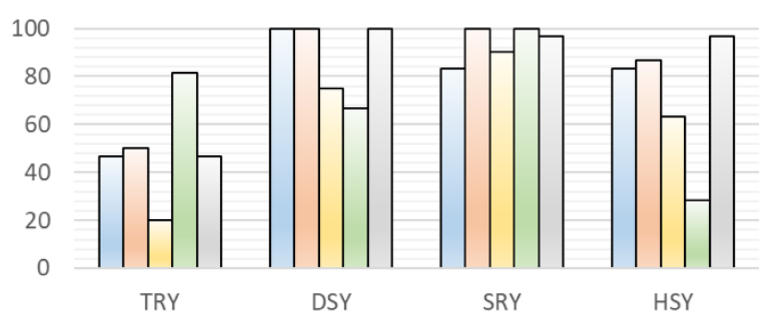

Figure S5 - The four considered weather files are compared in terms of their ranking as percentiles compared to the reference 30 years, following the five presented criteria for outdoor weather conditions for the city of Kolkata.

\section{Mumbai}

口TOmean5 口TOmean456 口TOmax5 口TOmax456 口WCDH

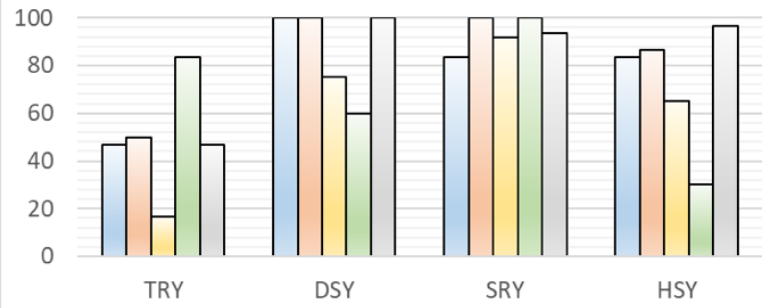

Figure S6 - The four considered weather files are compared in terms of their ranking as percentiles compared to the reference 30 years, following the five presented criteria for outdoor weather conditions for the city of Mumbai. 


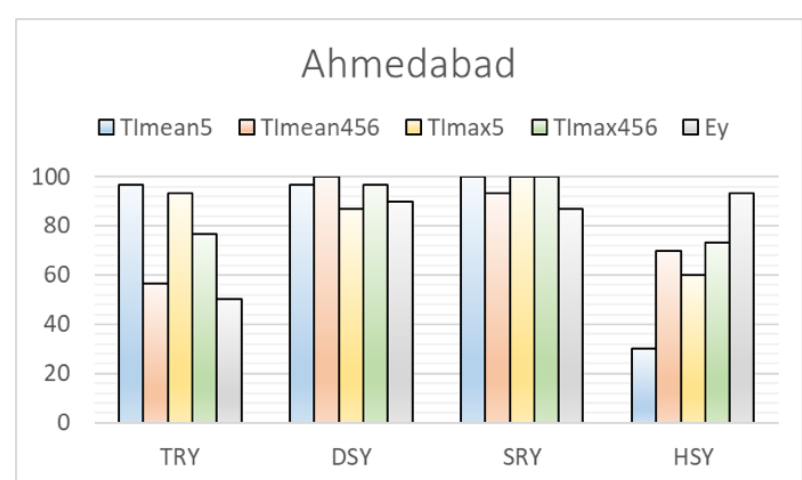

Figure S7 - The four considered weather files are compared in terms of their ranking as percentiles compared to the reference 30 years, following the five presented criteria for indoor conditions, for the city of Ahmedabad.

\section{Chennai}

口TImean5 口TImean456 口TImax5 口TImax456 口Ey

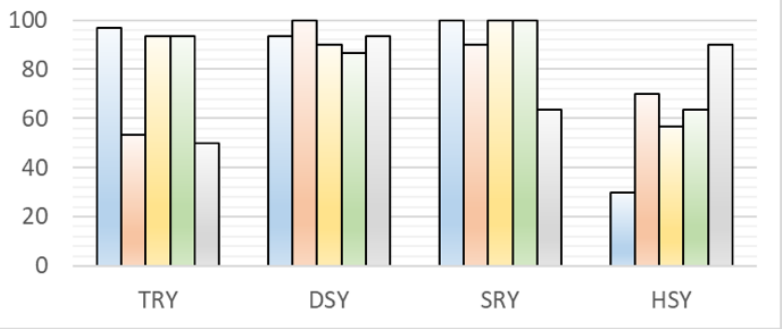

Figure S8 - The four considered weather files are compared in terms of their ranking as percentiles compared to the reference 30 years, following the five presented criteria for indoor conditions, for the city of Chennai.

Dehradun

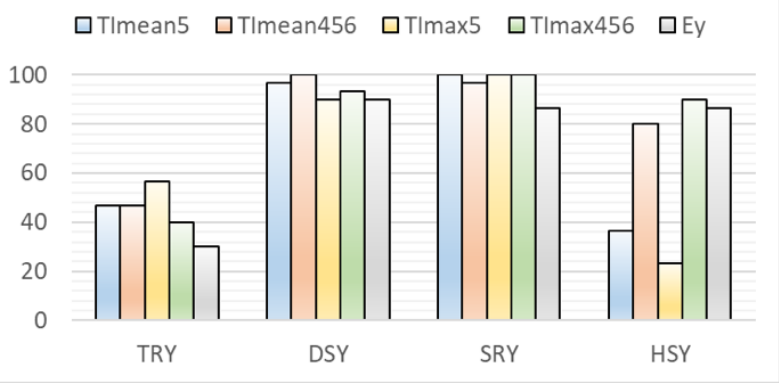

Figure 59 - The four considered weather files are compared in terms of their ranking as percentiles compared to the reference 30 years, following the five presented criteria for indoor conditions, for the city of Dehradun.

\section{Hyderabad}

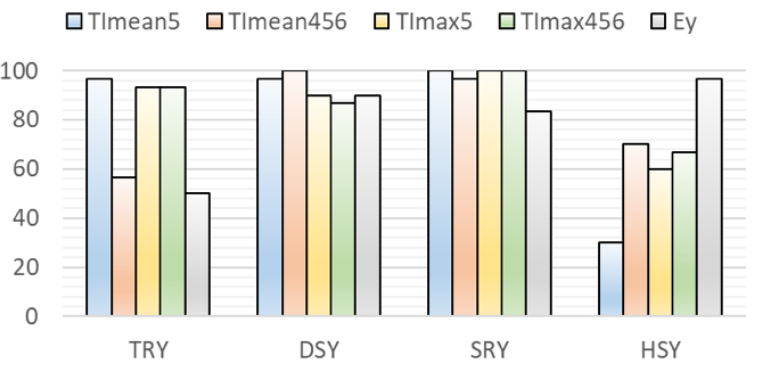

Figure S10 - The four considered weather files are compared in terms of their ranking as percentiles compared to the reference 30 years, following the five presented criteria for indoor conditions, for the city of Hyderabad.

\section{Kolkata}

口TImean5 口TImean456 口TImax5 口TImax456 口Ey

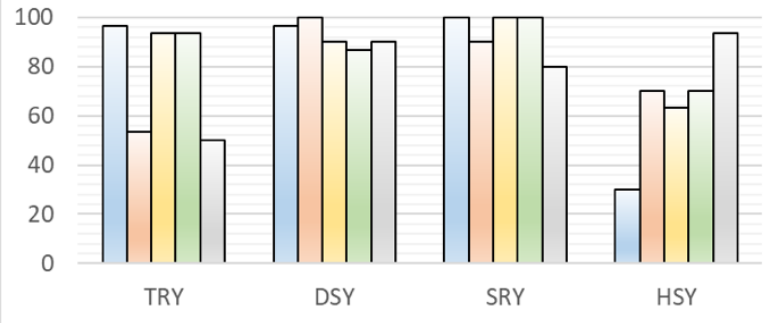

Figure S11 - The four considered weather files are compared in terms of their ranking as percentiles compared to the reference 30 years, following the five presented criteria for indoor conditions, for the city of Kolkata.

\section{Mumbai}

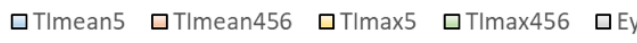

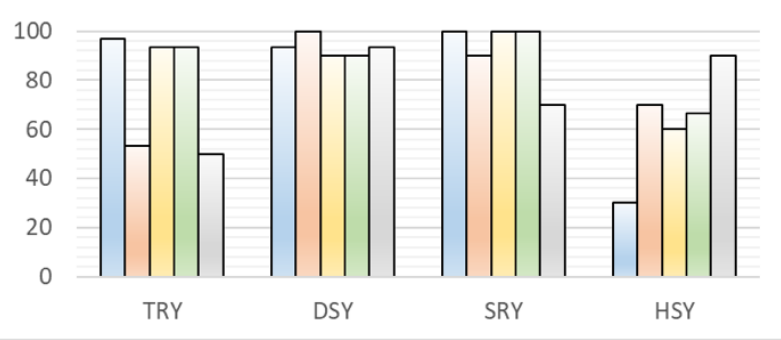

Figure S12- The four considered weather files are compared in terms of their ranking as percentiles compared to the reference 30 years, following the five presented criteria for indoor conditions, for the city of Mumbai. 